\title{
Atypical Presentation of Traumatic Neuroma: A case report
}

\author{
Bela Agrawal $^{1}$, Ajit Kumar Yadav $^{1}$, Khushboo Goel ${ }^{1}$, Sajeev Shrestha ${ }^{1}$, Ashish Shrestha ${ }^{2}$ \\ ${ }^{1}$ Department of Periodontology and Oral Implantology, ${ }^{2}$ Department of Oral Pathology and Microbiology, \\ BP Koirala Institute of Heal Sciences, Dharan, Nepal
}

\section{Correspondence \\ Dr. Bela Agrawal \\ Department of Periodontology \\ and Oral Implantology, BP \\ Koirala Institute of Heal \\ Sciences, Dharan, Nepal \\ Email: \\ belaagrawal@yahoo.com \\ DOI: http://dx.doi.org/10.3126/ jemsn.v13i3.18407}

Orcid ID: orcid.org/0000-00020315-166X

Article received: June $5^{\text {th }} 2017$ Article accepted: Sept $1^{\text {st }} 2017$

\begin{abstract}
Congenital Traumatic neuroma is a rare disorder that represents a reactive proliferation of neural tissue followingdamage to an adjacent nerve. Rarely these lesions appear in the oral cavity with certain predilection for the mental foramen and the tongue area. However, its presentation on lip is more unusual with only few cases being reported in the literature. Typically diagnosed in middle-aged women, patient complains of pain as a frequent symptom. Clinically, the lip lesions appear as a normal or grayish white nodule with a smooth surface that typically resembles a mucocele. We report here a case of a 37-year old female who presented with similar signs and symptoms and was diagnosed clinically as a mucocele. However, histopathological examination revealed it as a traumatic neuroma that was surgically excised. The patient is under follow-up with no signs of recurrence for 18 months.
\end{abstract}

Key words: Mucocele; Rare disorder; Traumatic neuroma

Citation: Agrawal A, Yadav AK, Goel K, Shrestha S, Shrestha A. Atypical Presentation of Traumatic Neuroma: A case report. JCMS Nepal. 2017;13(3):366-9.

\section{INTRODUCTION}

Traumatic neuromas are very rare with only a few cases reported in the English literature. ${ }^{1}$ Traumatic neuroma is an exuberant, but non-neoplastic proliferation of a nerve occurring in response to an injury or surgery. The principal features of oral traumatic neuroma are similar to traumatic neuromas elsewhere in the body. The ethiopathogenesis is an exaggerated response to nerve injury, in most of the cases after direct trauma or surgical manipulation, with development of reactive hyperplasia and are not considered true neoplasms in origin. ${ }^{2}$

After a nerve has been crushed or transected due to trauma or surgery, the proximal portion attempts to regenerate and re-establish innervation of the distal segment via the growth of axons through tubes of proliferating Schwann cells. Aberrant repair occurs when the regenerative tissues encounter a scar or otherwise cannot reestablish innervation. A tumour- like mass may then develop at the site of injury. ${ }^{3}$

In oral tissues, the lesion usually appears clinically as a nodule of normal or grayish white smooth surface coloration $^{4,5}$ with a predilection for the mental foramen area, tongue or lower lip., Traumatic neuromas occur in a wide age range, but are typically diagnosed in middle-aged women, ${ }^{4}$ who may complain of pain as a frequent symptom. ${ }^{5,7}$ Traumatic neuroma of the oral mucosa is mainly found in the gingiva after tooth extraction. Involvement of the lower lip is rare and only a few cases were reported in the literature. ${ }^{8}$

The microscopic appearance of the traumatic neuroma are characterized according to four variables: (1) stroma, (2) vascularity, (3) inflammatory infiltrate, (4) neural tissue pattern. Electron microscopy of the traumatic neuromas is highly characteristic and features multiple small nerve fascicles surrounded by collagen fibers. Each fascicle contains myelinated and unmyelinated 
axons, both of which are associated with Schwann cells. Small unmyelinated axons are predominated. All axons have electronluscent cytoplasm containing numerous neurofilaments and neurotubules. ${ }^{4}$ We report a case of a painless lower lip traumatic neuroma that was clinically misdiagnosed as a mucocele.

\section{CASE DESCRIPTION}

A 37-year-old female presented with the chief complaint of painless swelling on inner side of the lower lip since six months. She gave the history of lip biting. There was no history of trauma or surgery on the oral lesion site and her medical history was non-contributory. On examination, a soft, round, non-tender and fluctuant swelling of approximately $2 \mathrm{~mm}$ in diameter covered my normal mucosa was present.(Figure 1)The clinical impression was consistent with mucocele. The lesion was removed by excisional surgery. (Figure 2 to 4) Under proper asepsis and adequate local anesthesia a superficial incision was given in the midline and with the help of artery forceps the lesion was enucleated intact. The excised tissue was sent for histolopathological examination and it was diagnosed as traumatic neuroma.

Microscopic examination revealed a well circumscribed area containing haphazardly arranged fascicles of mature nerve tissue in a fibrous to myxomatous stroma. (Figure 5) Numerous endothelial cell lined blood vessels engorged with RBCs were evident. Focal areas revealed mild infiltration of lymphocytes. Microscopic analysis showed a haphazard proliferation of prominent nerve fascicles, including axons with their investitures of myelin, Schwann cells, and fibroblasts, embedded in a fibrotic stroma, with focal areas of hyalinized collagen. Characteristic clefts-like spaces between the stroma and nervous component were also observed. A large mature ganglion cell cluster surrounded by satellite cells and nerve fiber bundles was also

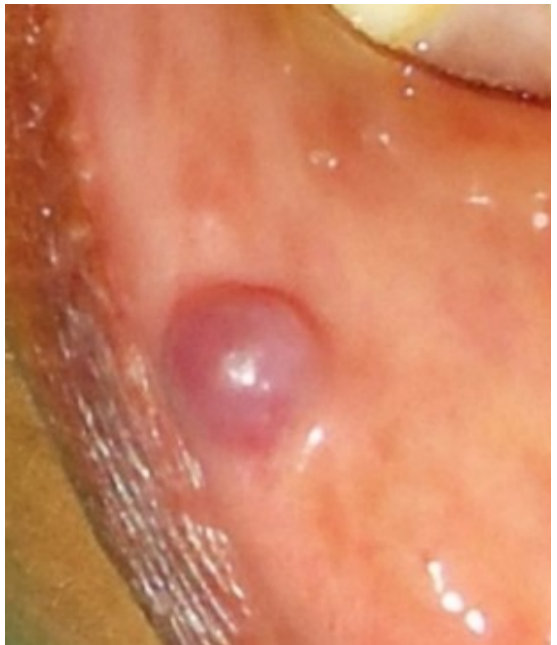

Figure 1 a

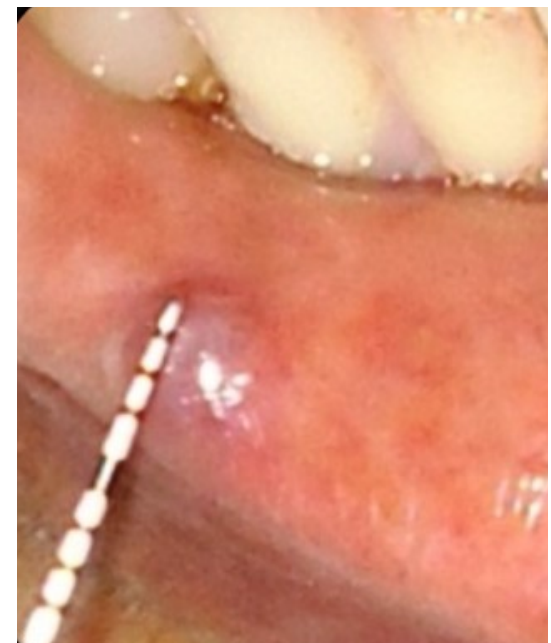

Figure 1 b

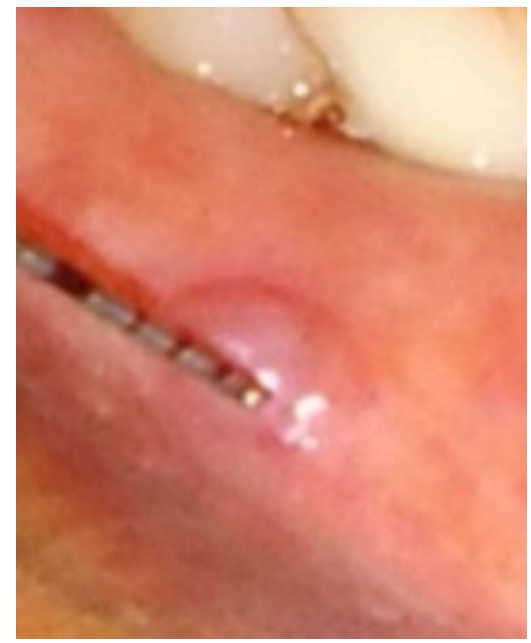

Figure 1 c

Figure 1: Pre-operative

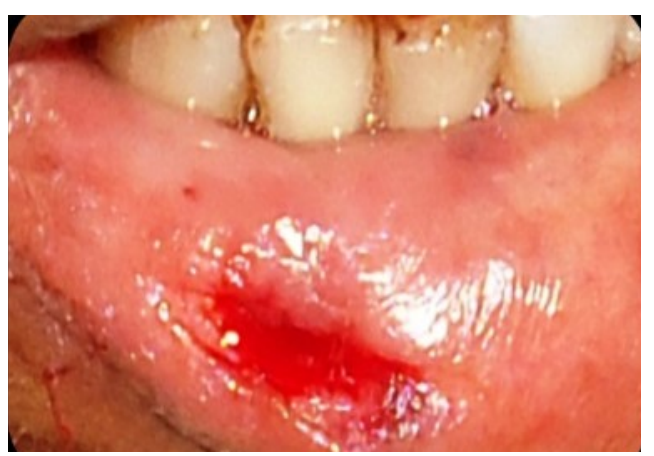

Figure 2: After excision

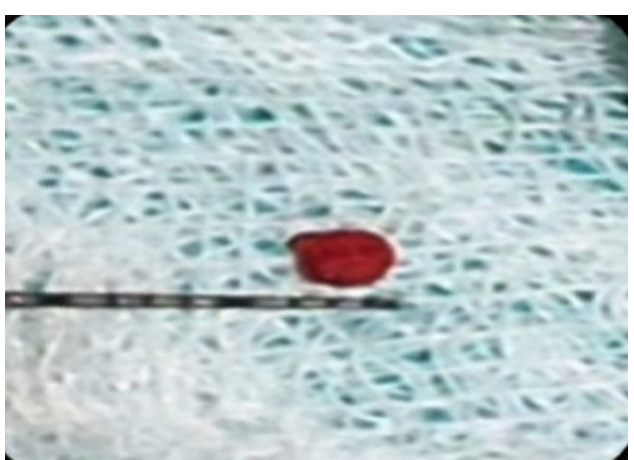

Figure 3: Excised mass 


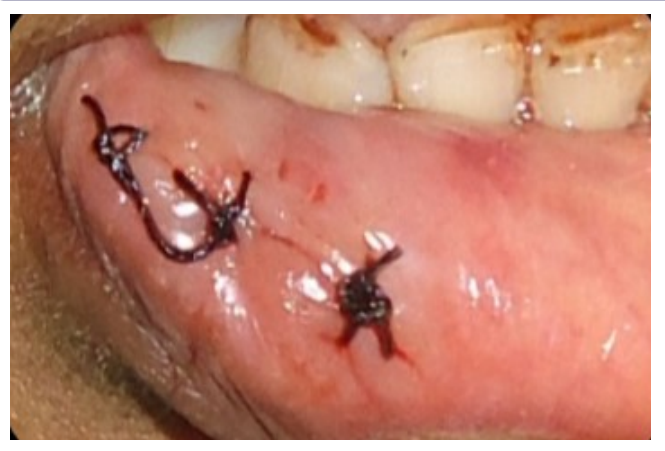

Figure 4: After suture placement

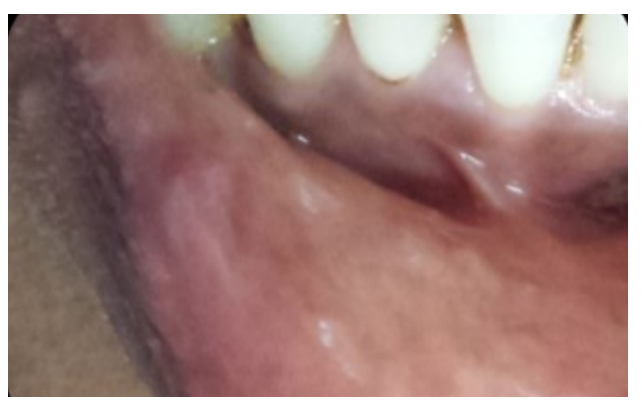

Fig. 5 a. $40 x$

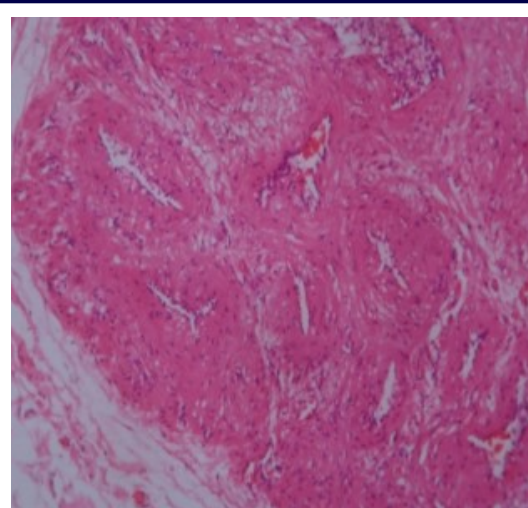

Fig 5 b. $100 x$

Figure 5: Histopathological examination

\section{Figure 6: After 12 months follow-up}

found within the stromal fibrosis. These histological features corresponded to traumatic neuroma with mature ganglion cells. The patient has been in follow-up for one year without signs of recurrence. (figure 6)

\section{DISCUSSION}

This Oral mucosa has a rich nerve supply which lies in the underlying connective tissue or mucosal appendices such as minor salivary glands. Any surgical procedure or chronic trauma is always traumatic to the hard and soft tissues and may lead to cutting the nerve fascicles. Rarely, the ends of the severed nerve cannot be re-established and abnormal proliferation of Schwann cells results in the formation of a mass of neural elements, named traumatic neuroma $(9,10)$. The symptoms may vary. This may appear as a painful or painless swelling.

As the name indicates, a history of trauma usually precedes the development of traumatic neuroma, such as an accident,an oral surgical procedure or impingement of an ill-fitting denture (11). Sist and Greene (4) studied 31 cases of oral traumatic neuromas, and most patients were 40 years or older and female. Only one neuromaswere in the lower lip and buccal mucosa, sites associated with tissuetraumatizing habits or accidents. Similarly, in our case 37 years old female presented with lesion in the lower lip where the patient had habit of lip biting. There is an extremely strong possibility that the nerve fibres might have been injured while bitingthus causing the neuroma. Vora et al (12) conducted a light microscopy study and raised the hypothesis that in patients with oral traumatic neuroma, there is an association between inflammation observed in histological studies of biopsy specimens and the symptoms of pain or tingling. In the case presented also, the patient had no complaints of pain and chronic inflammatory cells were only rarely found throughout the stroma of the lesion.

The treatment of choice for traumatic neuromas is surgical excision. An optimal technique with minimal manipulation and severance of nerve fibresisessential for an adequate outcome (10). Most lesions do not recur, but in some symptomatic cases, the pain may persist or return at a later date $(1,3)$.

\section{CONCLUSION}

Traumatic neuroma, though a rare disorder can occasionally be encountered and can clinically be misdiagnosed. The present case demonstrated the importance of considering traumatic neuroma in the differential diagnosis of painless mucosal swelling in lip.Surgical excision followed by histopathological examination is the treatment of choice.

\section{REFERENCES}

1. Rasmussen OC. Painful traumatic neuromas in the oral cavity. Oral Surg Oral Med Oral Pathol. 1980 Mar;49(3):1 https://doi.org/10.1016/0030-4220(80)90043-2.

2. Batsakis JG, Regezi JA. The pathology of head and neck tumors: salivary glands, part 4. Head Neck Surg. 1979 Mar 
-Apr;1(4):340-9. https://doi.org/10.1002/hed.2890010407 PMID: 227818.

3. Neville BW, Damm DD, Allen CM, Bouquot JE. Oral and maxillofacial pathology. $2^{\text {nd }}$ Ed. Philadelphia: WB Saunders; 2004: 454-5.

4. Sist TJ, Greene G. Traumatic neuroma of the oral cavity. Report of thirty-one new cases and review of the literature. Oral Surg Oral Med Oral Pathol. 1981;51:394-402. https:// doi.org/10.1016/0030-4220(81)90149-3.

5. Rasmussen O. Painful traumatic neuromas in the oral cavity. Oral Surg Oral Med Oral Pathol. 1980;49:191-5. https://doi.org/10.1016/0030-4220(80)90043-2

6. Flaitz C. Traumatic neuroma of the anterior tongue. Am J Dent. 2000;13:227-8. PMID: 11763938.

7. Regezi JA, Sciubba JJ, Jordan RCK. Oral pathology: clinical pathologic correlations. Ed. 5, St Louis: Saunders Elsevier.2008: 167-8.

8. Tashiro A, Imafuku S, Furue M. Traumatic neuroma of the lower lip with intraepithelial nerve fibers. J CutanPathol. 2008;35:320-3. https://doi.org/10.1111/j.16000560.2007.00801.x.

9. Zhang M, Hayashi H, Fukuyama H, Nakamura T, Kurokawa H, Takahashi T. Traumatic neuroma in the lower lip arising following laser/cryosurgery to treat a mucocele. Oral Dis. 2003; 9:160-1. https:// doi.org/10.1034/j.1601-0825.2003.02917.x PMID: 12945599.

10. Arribas-García I, Alcalá-Galiano A, Gutiérrez R, Montalvo-Moreno JJ. Traumatic neuroma of the inferior alveolar nerve: a case report. Med Oral Patol Oral Cir Bucal. 2008 Mar 1;13(3):E186-8. PMID: 18305440.

11. Flaitz C. Traumatic neuroma of the anterior tongue. Am J Dent. 2000;13:227-8. PMID: 11763938.

12. Vora AR, Loescher AR, Craig GT, Boissonade FM, Robinson PP. A light microscopical study on the structure of traumatic neuromas of the human lingual nerve. Oral Surg Oral Med Oral Pathol Oral RadiolEndod. 2005; 99:395-403. https://doi.org/10.1016/j.tripleo.2004.08.011 PMID: 15772589. 